In the last stage of life, his whole surface is leaden or blue and cold, and he lies pulseless often for hours; and, though so icy cold to the touch, throws off his bed-clothes, instinctively seeking through the skin more oxygen for the carbonised blood stagnating in his capillaries.

Some years ago, a pastrycook here went into his ice-well, and was asphyxiated by carbonic acid gas there. Shortly afterwards, when his dead body was brought up, it was as blue and leaden and livid as a cholera corpse. He died of carbonised blood.

It is true that respiration goes on to the last in cholera; but pathological anatomy shows that the mass of blood in the body is venous. The pouring out of the watery parts of the blood and its salts leaves the corpuscles without life, and in a short time incapable of being re-vitalised. The object and hope is, to stop this white hæmorrhage before the red corpuscles are incapable of re-oxygenation.

Now, if we consider the large surface of the skin which is reddened by a hot mustard bath and the rapidity of the circulation, the bath itself must, by this reddening process, be a powerful agent towards arterialising the whole mass of blood, and thus in giving more life. A blood-corpuscle does not take a minute to complete the whole circuit of the body. Each corpuscle thus reddened, and therefore more highly vitalised, passes on to the heart, and its place is instantly taken by another, subjected to the same process, and so on in every capillary vessel subjected to the heat and stimulus in an ever-flowing stream, and so rapidly that each makes the whole circuit (though it does not return to the same spot) in less than a minute of time. The amount of corpuscles so reddened in half an hour must be very considerable. I can only explain in this manner the rapid restoration to good health and strength in the cases related; and, if so, the hope that this treatment early employed may diminish the pernicious after-effects of the devitalised corpuscles in the vessels, only to be got rid of, if at all, by an after-fever.

From this reasoning, it follows that the reddening stimulus to the skin must be over a large surface, and continued for a considerable length of time, and tried early, before the blood-corpuscles have altogether lost the power of becoming oxygenated. And the test that the remedy has been applied in time would be in its reddening effects on the surface. If no reddening were produced, the hot mustard-bath would have been applied too late.

In the early stage of the hatching of an egg, the red corpuscles may almost be seen to be formed out of the yellow yolk, by equable, continual warmth and air-a process of the same kind as this, but a slower one, and by heat and air alone. Here heat is combined with a stimulant of the nerves, which goes to explain the rapid action of the joint means. For here is direct heat to re-vitalise the corpuscles, and a powerful excitant of nerve-force to circulate them more rapidly and to rouse the sluggish powers.

The rationale of this is the conversion of physical into vital forces.

Very hot water and mustard over a large surface is one of the most powerful vitalising agents we can employ.

On the continent, the grocers sell "mustard bran" for mustard foot baths and poultices, which our neighbours much use; but it is not to be procured in our shops. From the kindness of a lady who sent a quantity of it, which she obtained at Colman's, 26, Cannon Street, London, to the Infirmary here, I find that it is much stronger than common mustard, both in poultices and baths; and, as it is only three pence a pound, it should be introduced generally into this country for external use.

\section{ABSTRACT OF A PAPER ON CHOLERA.}

By P. O'CaLlaGhan, LI.B. and LL.D.Dub., and

D.C.L.Oxon; formerly Surgeon in the 11th

(Prince Albert's Own) Hussars.

[Read before the Social Science Association, October 6th, 1865.]

IN the year 1832 I happened to have medical charge of the garrison of Limerick, under the district superintence of the late Sir James Pitcairn, during the memorable outbreak of spasmodic cholera. I believe that the number of oholera cases in that garrison was nearly a third of those in the whole of the troops serving in Ireland at that time. My responsible and arduous duties on that occasion gave me the most favourable opportunities for studying this extraordinary disease, not only in the military hospitals, but likewise in the crowded civil establishments and refuges extemporised for the reception of the numerous cases of cholera in that populous city; and much subsequent experience and observation enabled me to test the value of the practical knowledge thus acquired.

Long before the idea was accepted, or even generally entertained, by the medical profession, I satisfied myself that the cholera was not a contagious disease, and that it was incapable of reproduction from the human body either alive or dead. I was also convinced that it was produced by a subtle atmospheric poison, borne along in suspension in the air, but not in chemical solution. It would, on this supposition, be likely to invade localities capriciously as it were, and in various degrees of intensity; and in general would be more under medical control in its advent and retrocession, because the poison would be at those times in smaller quantity and more diluted. I have been further convinced that this singular poison is material, and that its specific gravity is a little greater than the atmosphere, although it may be wafted forcibly in its strong currents; for I have observed that it had always a tendency to subsidence in calm and stagnant states of the air.

The latter supposition will serve to explain many of its strange phenomena. For instance, I have remarked that most persons were attacked towards morning, after they had lain several hours in a horizontal position, near the floors of their apartments, and probably immersed in the most polluted portions of the vitiated air during that time. It would occasionally happen, that even the lee-side of a ship might be alone infected, if the vessel had been sailing any length of time with a side wind.

I have observed the disease to stoop, as it were, and pounce upon a single bell-tent in a large camp, leaving all the others perfectly unharmed; and in another striking instance, I have seen one side of a large barrack-room attacked, although not a single case occurred on the opposite side, which was equally crowded. The immunity of the uninfected side in the latter case, appeared to me to have been cansed by the poisoned air having been blown over it through high windows, and deposited on the beds under the opposite wall.

From these observations it can be easily conceived that this terrible atmospheric poison is mainly influenced in its course by the direction of the winds, and that any locality in which it unhappily might prevail should look for a storm or strong gale of wind as the most merciful of all providential visitations; for I believe that neither the heat nor the cold, the humidity nor dryness of the air have the smallest influence in lessening its virulence.

If this theory should be true, it must follow that the worst localities are those in which the air is least circulated-such as narrow and crowded streets in 525 
low situations, enclosed courts, areas, cellars, etc. These unwholesome places are unluckily the most densely populated; and the physical condition of the inhabitants, from a combination of various causes, is in the worst possible state to resist infection, or struggle against disease.

It is therefore too hastily assumed that the locality, or sornething about the locality, is capable oi generating this peculiar poison; as if this state of things was new, and had not always existed even in a far worse degree than at present. The drainage is first accused as the " teterrima causa," next that universal culprit the water, then the graveyards, slaughter-houses, shambles, and even many of our most useful manufactories; in short, everything that produces a disagreeable smell. Nothing, however, appears to be more conclusively established than the fact, that smells are not noxious in proportion to their sensational offensiveness. On the contrary, there are good reasons for supposing that the agreeable fragrance of many perfumes, and in some cases the grateful odour of certain plants, become exciting causes of serious constitutional disturbance. For example, it is too well known that the pleasant scent of a newly mown hay-field, is far more injurious to many than the most noisome effluvium from a knacker's reeking slaughter-house.

This is not simply a theoretical idea, supported by mere assertion. Let any person of ordinary acuteness of observation take a morning walk through that most elegant, spacious, and best stocked of all gardens, Covent Garden; he cannot help being struck with the generally pale and unhealthy aspect of its occupants, who sit enthroned in their airy and wellventilated stalls, surrounded with piles of delicious fruits and gorgeous bouquets of sweet-scented flowers. If he will then take the trouble to extend his walk only a little way further, and try to wend his way through the narrow, close, and offensive purlieus of Newport Market, those loathsome depots and receptacles of animal matter in all its stages of decomposition, he will probably be compelled to hold a handkerchief before his nose; but he will see, at the same time with astonishment, the rosy and chubby cheeks of the boisterous children who inconveniently obstruct his way, and the florid glow of rude health in the countenance of their robust parents. The most eloquent leaders in the most popular journals should not delude the public into the unjust impression that the useful trades of the butcher, skin-dresser, gluemaker, chandler, etc., are more unhealthy occupations than those of the greengrocer, fruiterer, milliner bouquet-maker, etc. The contrary is the actual fact.

When the sewage of London was discharged into the Thames, a short time ago, the stench from the river at low water was exceedingly offensive. The whole of the press was unanimous in its clamorous demand for the suppression of such an alarming public nuisance, and London was menaced day after day with a pestilence which never came. On the contrary, the health-returns clearly proved that the metropolis was unusually free from epidemic disease on that occasion. My sole object, at present, is to urge with all the earnestness in my power the paramount duty of providing before-hand for the immediate removal of decided cases of cholera from infected localities. The necessity for making such preparations is, in my opinion, of the most vital consequence, not only for the more favourable treatment of the patients themselves, but likewise for the absolute safety of the medical officers and their attendants. In furtherance of this object I would recommend that all cholera hospitals should be made ambulatory where possible, or at all events easily and expeditiously removable. For such a purpose nothing appears to me to be so easily procurable, and so thoroughly available, as a large canvas tent. This suggestion, which was submitted many years ago to the consideration of the head of the Military Medical Department, I am happy to hear has been since occasionally adopted with the most beneficial results. I must confess I looked with serious apprehension upon a former recommendation of the General Board of Health-viz., that a medical staff should be organised for the purpose of house-to-house visitation, and the local treatment of cholera cases. As well might they have recommended that medical men should be sent down into foul mines, with the senseless object of resuscitating the unfortunate creatures whom they might find there gasping in the agonies of chokedamp.

In the town of Sligo, in 1832, no cholera hospitals were established, and the sick were all treated in their own houses. The consequences were appalling; most of the doctors, patients, and attendants were soon carried off, and that devoted town was rapidly decimated. I was, however, rejoiced at the authoritative recommendation of the central board for the early treatment of "premonitory symptoms." When the cholera visited this country a second time, I think in 1849, the 11th Hussars (of which regiment I was then surgeon) were quartered at Hounslow. The disease prevailed to a great extent in the neighbourhood, and was alarmingly fatal in the town and surrounding villages. Our barrack at that time was most unfavourably circumstanced. Its construction was bad, its ventilation and drainage very defective, and it was in great part enclosed by a foul and stagnant ditch.

My principal efforts then were directed to arrest, if possible, the disease in its first symptoms. For this purpose every barrack-room was supplied with a bottle of an astringent medicine, composed of the compound chalk mixture, catechu, and opium. This was given in charge to an intelligent non-commissioned officer, with orders to give a tablespoonful to every man who complained of the slightest premonitory symptoms, and even to repeat the dose if necessary before the man could be removed to the hospital.

This barrack-room self-treatment was attended with the happiest results, and was almost invariably successful. Few of such cases even required admission into the cholera ward; still fewer assumed an alarming character; and none proved fatal.

This is the arrangement which I would now venture to urge upon all local boards of health for general adoption. Let there be at once established convenient depôts for the immediate and gratuitous administration of this description of medicine, and appliances for the speedy removal of the decided cases either of rich or poor, from the infected atmosphere in which they may happen to be immersed, and I feel confident that under providence this dreaded visitation will become divested of much of its malignity, and much of its terror.

Not Acchimatised. The mortality returns of New York for the second week in October show that of the 262 deaths of children in the week, 203 are reported the uffspring of foreign parents, and only 59 of native parents. If life and death bore the same proportions in the entire population, the above figures would in dicate that of the $1,500,000$ residents within ten miles of the city hall at least 77 per cent. are foreigners. Of course, this is absurdly wrong; but the returns prove two things-foreigners produce five children where natives have two; and the former raise one where the latter raise three. (New York Times.) 